\title{
RESPOSTAS FISIÓLOGICAS DA ESPÉCIE Physalis peruviana SUBMETIDA A DIFERENTES DISPONIBILIDADES HÍDRICAS.
}

\author{
Francisco dos Santos Neto ${ }^{1}$; Lenaldo Muniz de Oliveira ${ }^{2}$; Ianna Freitas ${ }^{3}$; Viviane \\ de Jesus Carneiro \\ 1. Graduando em Agronomia, Universidade Estadual de Feira de Santana, e-mail: \\ franciscosantosn@ hotmail.com \\ 2. Orientador, Departamento de Ciências Biológicas, Universidade Estadual de Feira de \\ Santana, e-mail: lenaldo.uefs@gmail.com \\ 3. Co-orientador, Universidade Estadual de Feira de Santana, e-mail: \\ 4.Graduanda em Agronomia e participante do projeto, Universidade Estadual de Feira \\ de Santana, e-mail: vivianedjcarneiro@gmail.com
}

\section{PALAVRAS-CHAVE: FISALIS, DISPONIBILIDADE HÍDRICA, CLOROFILA}

\section{INTRODUÇÃO}

Phisalys peruviana, também é conhecida por uchuva (HAWKES, 1999), pertence a família das solanáceas, tendo seu desenvolvimentodentro de um casulo, feito por uma folha fina possuindo um formato de cálice (Moschetto, 2013). É nativa da Amazônia e dos Andes e vem sendo cultivada na Colombia e vem ganhando cada vez mais espaço no Brasil (SEVERO, 2010).

A espécie vem despertando interesse comercial por conta do alto potencial produtivo em regiões tropicais e subtropicais, além de apresentar grande valor nutricional e econômico agregado (NOVOA ET AL., 2006; RUFATO ET AL., 2008). Além disso, é uma espécie que tem um custo de produção relativamente pequeno, o que a torna uma boa opção aos médio e pequenos produtores (LIMA ET AL., 2010). Outro fator que torna a physalis atraente do ponto de vista dos produtores é que ela vem ganhando cada vez mais espaço no setor farmacêutico. Segundo Pérez-Castorena et al. (2012) a principal razão que torna a phisalys interessante, é a utilização na medicina popular em diversos países.

Apesar do crescente interesse pelo cultivo dessa espécie, ainda são necessárias mais informações sobre aspectos acerca do seu cultivo principalmente na região semiárida, onde fatores como a restrição hídrica, fator comum em regiões semiáridas. A falta de água pode ser um fator limitante de produção e, segundo Meng et al. (2016), a seca limita o desenvolvimento da planta e por consequência afeta a sua produtividade.

Diante disso, o presente trabalho teve como objetivo avaliar o comportamento da espécie Physalis peruviana em diferentes disponibilidades hídricas.

\section{MATERIAL E MÉTODOS}

As mudas foram produzidas a partir de sementes de $P$. peruviana, armazenadas no banco de sementes do Laboratório de Germinação (Lager), que foram colocadas em sementeiras de plástico preenchidas com substrato comercial e submetidas a irrigação automática. Para determinar a capacidade de campo dos vasos, foi feito um ensaio com três vasos preenchidos com solo, onde foram irrigados até a saturação e após 24 horas foram novamente irrigados com um volume conhecido de água, coletando-se a água percolada. Por diferença foi determinada água evapotranspirada no período de 24 horas. Foram estabelecidos níveis de água equivalentes a 100\%, 80\%, 60\%, 40\% e $20 \%$ da água evapotranspirada. 
Após 30 dias de cultivo, foram aplicados os tratamentos (100\%, 80\%, 60\%, 40\% e $20 \%$ da disponibilidade hídrica) onde a reposição era feita a partir dos resultados de pesagens diárias repondo o volume de água que a umidade do solo atingisse.

$\mathrm{O}$ conteúdo relativo de água (CRA) foi mensurado às 08:00 $\mathrm{h}$ em folhas totalmente expandidas localizadas no terço médio da planta. A determinação do CRA foi com base no peso de três discos foliares (Matéria Fresca - MF, Matéria Túrgida MT e Matéria Seca - MS), de acordo com a metodologia de Weatherley (1950), utilizando-se a seguinte fórmula: $\mathrm{CRA}=[(\mathrm{MF}-\mathrm{MS}) /(\mathrm{MT}-\mathrm{MS})] \times 100$. O potencial hídrico ( $\psi_{\mathrm{w} \text { foliar) }}$ foi no período de ante-manhã, usando uma câmara de Scholander (PMS 1000, PMS Instrument, Corvallis, USA), em folhas coletadas do terço médio das plantas.

A determinação do teor de clorofila foi realizada utilizando discos foliares de área conhecida que foram imediatamente imersos em $5 \mathrm{~mL}$ álcool 95\%, segundo Tanan et al. (2017). Os tubos foram vedados e envoltos em papel alumínio, mantidos por um período de aproximadamente 72 horas. Após a extração, foi realizada a leitura das amostras nasabsorbâncias de 664,2 e 648,6 nm em espectrofotômetro. Após a coleta de dados, foram feitos os cálculos dos teores de clorofila a e b, expressos em $\mathrm{mg} . \mathrm{cm}^{2}$, de acordo com as equações propostas por (LICHTENTHALER, 1987).

\section{RESULTADOS E/OU DISCUSSÃO}

No que se diz respeito às relações hídricas como conteúdo relativo de água (CRA) e potencial hídrico, estudos de Puértulas (2017) mostram que quando as plantas são submetidas a condições de disponibilidade de água abaixo do ideal as relações hídricas são influenciadas de forma negativa, o que corrobora com os resultados obtidos no presente experimento, onde estão representados os resultados referentes ao conteúdo relativo de água (Figura 1a), que permaneceram estatisticamente iguais até durante o tratamentos de $100 \%$ a $60 \%$ da disponibilidade hídrica.A partir do tratamento de $40 \%$ da $\mathrm{CC}$ os valores encontrados se apresentaram menores e começaram a diferir estatisticamente dos valores apresentados em plantas cultivadas com maiores disponibilidades hídricas, o que mostra que as plantas de Physalis peruviana apresentam uma tolerância de leve a moderada quando submetidas ao déficit hídrico, e provavelmente mantendo suas células ainda turgidas e hidratadas.

Resultados semelhantes foram encontrados por Leite (2019) em plantas de Physalis angulata que apresentaram ainda mais tolerância ao déficit quando se leva em consideração o conteúdo relativo de água, onde os resultados permaneceram estatisticamente iguais até $40 \%$ da disponibilidade hídrica. Vale ressaltar que as plantas mesmo em déficit conseguiram se reidratar no período da noite, mesmo com baixos níveis de água no solo, o que caracteriza uma característica de tolerância (LEITE, 2019).

Com relação ao potencial hídrico (Figura 1b), as plantas que não sofreram com déficit hídrico, os valores obtidos foram de aproximadamente -0,21 MPa e à medida que as plantas foram submetidas ao déficit, apresentaram valores mais negativos chegando em valores correspondente a $-0,816 \mathrm{MPa}$, no tratamento em que a disponibilidade hídrica foi de $20 \%$ da capacidade de campo. A redução do potencial hídrico pode estar relacionada com o acumulo de solutos orgânicos como açucares solúveis totais e redutores (LEITE, 2019), uma vez que os açucares são uma importante ferramenta reguladora e facilitadora de processos fisiológicos como a fotossíntese, germinação de sementes, partição do carbono, florescimento, senescência além de síntese de proteínas e expressão de genes sob estresses abióticos (ROSA et al., 2009; SAMI et al., 2016). 
Para o teor de clorofila (Figura 2) apresentado nas folhas de P. peruviana, o tratamento com $20 \%$ da capacidade de campo foi o que se destacou, com maiores valores, resultado que contraria autores como Larcher (2006) e Deveci \& Celik (2016) no estudo com $P$. peruviana, que relatam que em situações de déficit hídrico ocorre a degradação de clorofila. Tal aumento na quantidade dos pigmentos de clorofila indica que a $P$. peruviana apresenta resistência ao déficit hídrico o que pode indicar uma possível potencialização na assimilação de $\mathrm{CO} 2$ para que seu desenvolvimento seja mantido (MOURA et al., 2016).
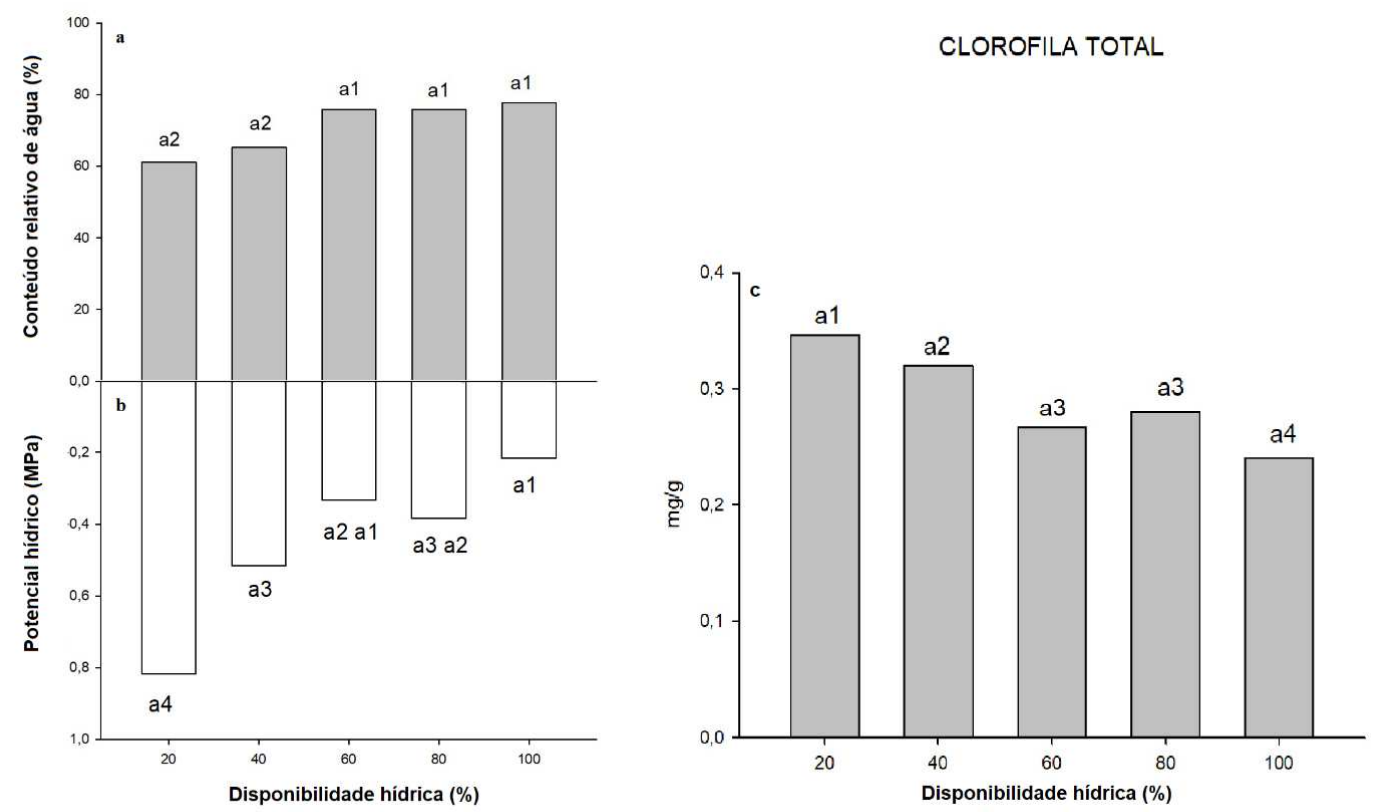

Figura 1: Conteúdo relativo de água (CRA) (a) e potencial hídrico(b) de plantas de Physalis peruviana em diferentes disponibilidades hídricas e clorofila total (c)

\section{CONSIDERAÇÕES FINAIS}

Conclui-se que as plantas de Physalis peruviana apresentam características que evidenciam uma possível tolerância ao déficit hídrico como o fato de conseguir manter suas células aparentemente ainda turgidas e hidratadas até $60 \%$ da disponibilidade hídrica, o que indica um melhor aproveitamento do uso da água. Houve também um aumento no teor de clorofila numa tentativa de que se possa manter seu desenvolvimento.

\section{REFERÊNCIAS}

HAWKES, J.G. 1999. The economic importance of the family Solanaceae. In:Soares, E.L. de C.; Vendruscolo, G.S. ;Vignoli-Silva, M.; Thode, V.A.; Silva, J.G. da; Mentz, L.A. Gênero Physalis L. (Solanaceae) no Rio Grande do Sul, Brasil. Pesquisas, Botânica Nº 60:323-340 São Leopoldo: Instituto Anchietano de Pesquisas, 2009. 
LIMA, C. S. M., GONÇALVES, M. A., TOMAZ, Z. F. P., FACHINELlO, J. C. \& RUFATO, A. R. (2010) Sistemas de tutoramento e épocas de transplante de Physalis. Ciência Rural, Santa Maria, 40, 1-8.

MENG, S.; ZHANGA, C.; SUA, L.; LIA, Y.; ZHAOA, Z. Nitrogen uptake and metabolism of Populus simonii in response to PEG-induced drought stress. Environmental and Experimental Botany, v. 123, p. 78-87, 2016

MOSCHETTO, A. disponível em: http://revistagloborural.globo.com/Globo Rural/0,6993,EEC1711098- 4529,00.html, 2013.

NOVOA, R. M., BOJACÁ, J., GALVIS, Y. G. \& FISCHER. (2006) La madurezdel fruto y el secado Del cálizinfluyenenelcomportamientoposcosecha de lauchuva (Physalis peruviana L.) almacenada. Bogotá, Agronomía Colombiana, v. 24, n. 1, p. 77-86, 2006.

PÉREZ-CASTORENA, A. L.; LUNA, M.; MARTINEZ, M. \& MALDONADO, E. New sucroseestersfromthefrutsofPhysalissolanaceus.CarbohydrateResearch, v.352, p. 211-214, 2012.

RUFATO, L., RUFATO, R. A., SCHLEMPER, C., LIMA, C. S. \& KRETZSCHMARA, A. (2008) Aspectos técnicos da cultura da Physalis. Lages, CAV/UDESC; Pelotas: UFPEL, p. 100

SEVERO, J. et al. ATIVIDADE ANTIOXIDANTE E FITOQUÍMICOS EM FRUTOS DE PHYSALIS (Physalis peruviana, L.) DURANTE O AMADURECIMENTO E O ARMAZENAMENTO. R. Bras. Agrociência, Pelotas, v.16, n.1-4, p.77-82, jan-dez, 2010. 